This is an electronic reprint of the original article. This reprint may differ from the original in pagination and typographic detail.

Author(s): Aunola, Kaisa; Selänne, Anniina; Selänne, Harri; Ryba, Tatiana V.

Title: The role of adolescent athletes' task value patterns in their educational and athletic career aspirations

Year: $\quad 2018$

Version:

Please cite the original version:

Aunola, K., Selänne, A., Selänne, H., \& Ryba, T. V. (2018). The role of adolescent athletes' task value patterns in their educational and athletic career aspirations. Learning and Individual Differences, 63, 34-43.

https://doi.org/10.1016/j.lindif.2018.03.004

All material supplied via JYX is protected by copyright and other intellectual property rights, and duplication or sale of all or part of any of the repository collections is not permitted, except that material may be duplicated by you for your research use or educational purposes in electronic or print form. You must obtain permission for any other use. Electronic or print copies may not be offered, whether for sale or otherwise to anyone who is not an authorised user. 
Running head: TASK VALUES AND EDUCATIONAL ASPIRATIONS

Running Headline: TASK VALUES AND EDUCATIONAL ASPIRATIONS

\author{
The Role of Adolescent Athletes' Task Value Patterns \\ in Educational and Athletic Career Aspirations \\ Kaisa Aunola $^{1 *}$, Anniina Selänne ${ }^{1}$, Harri Selänne ${ }^{2}$ \& Tatiana V. Ryba ${ }^{1}$
}

Authors' Note

*Kaisa Aunola (corresponding author), Department of Psychology, University of Jyväskylä, Finland; phone: +358 408053481, Fax: +358 142602801, email: kaisa.aunola@jyu.fi.

${ }^{1}$ University of Jyväskylä, Department of Psychology; ${ }^{2}$ Mehiläinen Sports Medical Clinic, Jyväskylä, Finland.

This study was funded by grant from the Finnish Ministry of Education and Culture (grant number OKM/13/626/2015) to Tatiana Ryba. 
The Role of Adolescent Athletes' Task Value Patterns

in their Educational and Athletic Career Aspirations 


\begin{abstract}
The present study examined the stability and change in task value patterns that Finnish studentathletes $(n=391)$ show during their first two years in upper secondary sport school and the extent to which these patterns, and changes in them, are associated with students' future educational and athletic career aspirations. By using latent profile analysis, three different and highly stable motivational patterns were identified among adolescents: (1) a dual motivated pattern, characterized by high value placed on both school and sport; (2) a low academically motivated pattern, characterized by a high value placed on sport but a low value on school; and (3) a relatively low sport motivated pattern characterized by a lower value placed on sport than was typical for the sample. The results further showed that the task value patterns and the changes in them over the two year study period were related to the students' educational and athletic career aspirations even after controlling for the impacts of their grade point average, gender, type of sport, and level of sport competition. Compared to the other students, those showing a dual motivated pattern were more likely planning to continue their studies at university after upper secondary school than might be expected by chance. The students who showed a low academically motivated pattern, in turn, were less likely than the others to aim for university and were more likely to plan to have a professional career in sport. Those who showed a relatively low sport motivated pattern were under-represented among those who planned to make sport their professional career.
\end{abstract}

Keywords: task values, student-athletes, dual career, educational aspirations, person-oriented approach 
The Role of Adolescent Athletes' Task Value Patterns

in their Educational and Athletic Career Aspirations

In recent years, there has been increasing societal expectation in Nordic countries that athletes will simultaneously succeed in sport and at school (Christensen \& Sørensen, 2009; XX et al., 2016; Authors removed for review purposes). However, previous research on dual careers in sport and education has shown that succeeding in both is highly demanding due to, for example, time constraints, overlapping schedules, and conflicting goals (for a review, see Stambulova \& Wylleman, 2015). Moreover, student-athletes tend to prioritize sport over school (Adler \& Adler, 1985; Cosh \& Tully, 2014; Simons, Van Rheenen, \& Covington, 1999), which may diminish not only their possibility of succeeding in academics but also narrow their thinking about and planning for their future education and vocational career. However, thus far, there has been a lack of systematic longitudinal research on the development of student-athletes' values and future aspirations. Little is therefore known about the kind of value patterns student-athletes show when constructing a dual career, and how these patterns are reflected in their educational and career aspirations. Consequently, the present study aimed to examine the patterns of task values that student-athletes have at the beginning of upper secondary school, how stable these patterns are across the first two years of upper secondary school, and how these patterns are related to the student-athletes' future educational and athletic career aspirations.

The term "dual career" refers to the athlete's challenge of combining an elite sporting career with education/work (EU Guidelines on Dual Careers of Athletes, 2012). From the developmental perspective, athletes face unique challenges throughout their sporting lifespan, which include psychological, social, academic/vocational, and financial challenges. As conceptualized by the Holistic Athletic Career model (Wylleman \& Lavallee, 2004; Wylleman, Reints, \& De Knop, 2013), and adapted to the Finnish context by XX et al. (2016; Authors removed for review purposes), athletes' developmental transitions in sport are in concurrent and reciprocal interaction with 
transitions occurring in other life domains, such as their educational and vocational development. The promotion of dual careers to ensure that young athletes receive education and vocational training together with their sporting training reflects the Europe 2020 Strategy, which emphasizes the prevention of school dropouts, a larger number of graduates from higher education, and better youth employability.

In order to successfully manage a dual career, students have to be motivated toward both education and sport. This is evident as motivation has been shown to play an important role in task engagement and persistence both in sport (Pelletier, Fortier, Vallerand, \& Brière, 2001) and in education (Kuh, Cruce, Shoup, Kinzie, \& Gonyea, 2008; Pintrich, 2003); whereas a lack of motivation has been shown to increase the risk of dropping out from sport (Jõesaar, Hein, \& Hagger, 2011; Sarrazin, Vallerand, Guillet, Pelletier, \& Cury, 2002) and from school (Vallerand, Fortier, \& Guay, 1997). Although the early literature on dual career research includes some evidence of a negative association between high performance in sport and academic success (Adler \& Adler, 1985; Purdy, Eitzen, \& Hufnagel, 1982), more recent studies suggest that talented athletes tend to be highly motivated to do well in both domains (Durand-Bush \& Salmela, 2002; Lupo et al., 2015; Lupo et al., 2017; Umbach, Palmer, Kuh, \& Hannah, 2006). A limitation of the earlier research is that it mainly focused on examining the dual careers of university-level athletes (e.g., Adler \& Adler, 1985; Gaston-Gayles, 2004; Lupo et al., 2015; Simons et al., 1999); thus, less is known about the challenges of talented and elite youth athletes in combining sport and education during the earlier stages of their development (Stambulova, Engström, Franck, Linnér, \& Lindahl, 2015). Because many athletes experience a transition in their competition level from junior to senior level during the time of their transition to upper secondary education - and this transition is known for its high dropout rate from sport (approximately 70\%; Bussmann \& Alfermann, 1994) — this period might be assumed to be crucial in determining the successful dual career development of athletes. 
One widely used theoretical framework for motivation is the Eccles' Expectancy-Value model (Eccles et al., 1983; Eccles \& Wigfield, 2002), according to which students' achievements and task choices are determined not only by expectancies for success but also by subjective task- or activityrelated values, that is, the values individuals attach to a specific option. According to the model, the value of a specific task or activity can be differentiated into three components: attainment value refers to the personal importance of doing well on a task/activity; intrinsic or interest value refers to the simple enjoyment one gets from engaging in an activity; and utility value refers to the short- or long-term importance and usefulness of a specific task/activity. The model further theorizes that the value a person places on a certain task or activity predicts his or her future engagement with that activity.

In line with the model, students' task values have been related to various achievement outcomes, such as level of performance, persistence, amount of effort put into learning situations, and course choices relative to population-based samples (Bong, 2001; Eccles et al., 1983; Eccles, 2005; Wigfield \& Eccles, 2000). In addition to these short-term consequences, students' task values may, however, also contribute to the ways in which they think about and act upon their future lives, particularly in the domains of education and career (Lazarides, Viljaranta, Aunola, Pesu, \& Nurmi, 2016; Lupo et al., in press a). This kind of thinking about and planning for the future are important developmental tasks during adolescence (Nurmi, 1989; Nurmi, Seginer, \& Poole, 1995). In previous research using population-based samples, students' task values have been shown to play an important role in their educational plans and aspirations (Eccles, 2005; Eccles, Vida, \& Barber, 2004; Lazarides et al., 2016; Viljaranta, Nurmi, Aunola, \& Salmela-Aro, 2009; Watt et al., 2012) as well as in their occupational aspirations and career choices (Eccles, 2005; Eccles et al., 1998; Viljaranta et al., 2009). For example, in the study by Viljaranta et al. (2009), 16-year old adolescents with high task values across school domains, or in mathematics and science in particular, were over-represented among students who selected the academic track after comprehensive school and under-represented 
among students who selected a vocational track. Similarly, in the study by Lazarides et al. (2016), when compared with secondary school students who demonstrated a motivational pattern characterized by high values placed on practical subjects at school, those students who showed a highly motivated or math-motivated pattern (as defined by subjective task values) were more likely to aim for a degree from a university.

Although task values might be assumed to play an important role among adolescent athletes when they construct their identities and plan for their future, little is known about their task value development and the role of task value patterns in student-athletes' future goals and aspirations when they are constructing a dual career. The few studies carried out have focused mainly on the academic motivation and aspirations of tertiary-level student-athletes (e.g., Fortes, Rodrigues, \& Tchantchane, 2010; Gaston-Gayles, 2004; Lupo et al., 2015; Lupo et al., in press b). However, planning for the future is seen as an important developmental task, particularly during adolescence (Lally \& Kerr, 2005; Nurmi, 1989; Nurmi et al., 1995). Moreover, because secondary education is typically viewed as an inevitable part of youth in most industrialized nations (Pless, 2014), many adolescent athletes involved in secondary education may find it difficult to persist at school if their life goals, dreams, and career aspirations are disconnected from their education (XX et al., 2017; Authors removed for review purposes). Consequently, the aim of the present study was to discover the patterns of task values that student-athletes show in upper secondary school, how these develop over their years at school, and how these patterns are related to their educational aspirations, on the one hand, and to their athletic career aspirations, on the other. To identify these patterns, a person-centered approach on the data was utilized. This approach made it possible to identify subgroups of student-athletes who show different patterns of task-values. Whereas a variable-centered approach applies a single model to the whole sample to estimate a single set of parameters, a person-centered approach is able to relax the assumption of homogeneity in the population through the estimation of a distinct set of parameters applicable to the various subgroups present in the sample (Mäkikangas, Tolvanen, 
Aunola, Feldt, Mauno, \& Kinnunen, in press). In addition to identifying subgroups of studentathletes who demonstrate different patterns of task-values, the person-centered analysis provided also other benefits compared to variable-centered approach, including information about the proportion of the sample belonging to certain identified subgroup.

The present study was carried out in Finland. In the Finnish educational system, after completing 9 years of basic education, at the age of 15 or 16, adolescents make a decision regarding their secondary education. Secondary education comprises upper secondary (considered to be an academic track that prepares students to apply for higher education in university) or vocational high school (professional preparation). After upper secondary school, students may apply to universities or to polytechnic schools. After vocational school, students often transit to work or continue in polytechnic schools. Talented and elite youth athletes in Finland often pursue secondary education within the national talent development program that structurally enables the construction of a dual career pathway. Specialized sports upper secondary schools ("urheilulukiot" in Finnish) collaborate with athletic clubs and sport federations to arrange morning practices for athletes, offer the possibility of extending the 3-year academic curriculum to 3.5 or 4 years, give some study credits for sport, and assist with dual career planning. Currently there are 13 upper secondary sport schools in Finland, labeled sport high schools by the Ministry of Education and Culture. The admission to upper secondary sport schools is competitive, and in addition to the students' grades in their secondary school reports, in order to be accepted, the students must demonstrate strong potential in their own sport. Because of the competitiveness of admission to upper secondary sport schools, students accepted to these schools have, on average, higher level of school achievement in comprehensive school in terms of grade point average (GPA) than students in regular upper secondary schools.

\section{Aims of the Study}

The present study examined the following research questions: 
1. What patterns of task values do student-athletes in the upper secondary sport schools show? How stable are these patterns? What proportion of athletes show a particular pattern of task values? Because recent studies suggest that talented and elite athletes tend to be highly motivated to do well in both sport and education (Durand-Bush \& Salmela, 2002; Lupo et al., 2015; Umbach et al., 2006), we expected to find a relatively large group of athletes who showed high task values in both sport and education (H1). However, because there are individual differences in athletes' school and sport motivation due, for example, to the level of their GPA or the type of sport played, we also expected to find domain-specific task value patterns (H2). Because no previous studies have investigated the changes in task values over time among student-athletes, no hypotheses were set regarding the stability and change of task value patterns.

2. How do the patterns of task values, and the changes in them, relate to the athletes' future educational and athletic career aspirations? Past studies have shown that students who put a high value on a certain achievement domain also show high future expectations and aspirations in that particular domain (Eccles, 2005; Lazarides et al., 2016; Viljaranta et al., 2009). Consequently, it was expected that athletes who reported high task values for education, were more likely to plan to continue to university after upper secondary school than others (H3), whereas those reporting high task values for sport, in particular, were more likely to plan to have a professional career in sport (H4).

Because the level of school achievement (Berndt \& Miller, 1990; Rimkute, Hirvonen, Tolvanen, Aunola, \& Nurmi, 2012; Viljaranta et al., 2009), gender (Viljaranta et al., 2009), and type of sport or level of sport competition (Lupo et al., 2015; McCarthy, Jones, \& Clark-Carter, 2008) might be assumed to be related to the students' educational and/or athletic career aspirations, as well as to their task values (e.g., Eccles et al., 1983; Eccles \& Harold, 1991; Meece, Glienke, \& Burg, 2006; Viljaranta et al., 2009), the possible impact of these variables was taken into account when predicting athletes' aspirations in relation to their task value patterns. 
The study is part of the ongoing longitudinal study on Finnish student athletes (XX et al., 2016; Authors removed for review purposes). In the present manuscript submitted to Learning and Individual Differences two previous papers using the same dataset and written by the authors are referred. One of these (referred in the present manuscript as XX et al., 2016) describes the overall study protocol and reviews the previous literature related on student-athletes' dual career research. The other paper (referred in the present manuscript as XX et al., 2017) uses qualitative methods to examine how and to what extent Finnish adolescent athletes narrate and integrate significant life events in sport and education into their identity and future narratives to glean an understanding of the athletes' career construction style. The two papers described above do not focus or use measures used in the present paper submitted to Learning and Individual Differences although in the protocol article (XX et al., 2016) these measures are listed among other measures as part of the ongoing longitudinal study. There are also other articles published from the used dataset but not referred in the present manuscript. However, because the focus of these previous studies has not been on task values, or on educational and career aspirations, the present study has unique contribution given those existing works.

\section{Method}

\section{Participants}

The sample for the present study was drawn from the ongoing Finnish Longitudinal Dual Career Study (XX et al., 2016; Authors removed for review purposes) that follows student-athletes from the beginning of upper secondary school to the end of upper secondary school. At the beginning of the study, a total of 391 (51\% females) athletes from six different sport high schools in Finland (two each from the Northern, Central, and Southern parts of Finland) were invited to participate. All invited athletes participated in the study. At the start of the study, the students were 15-16 years old. A total of $50 \%$ of them represented individual sports and $50 \%$ team sports. Twenty percent of the athletes participated in Winter Olympic sports (e.g., alpine skiing, cross country 
skiing, ice hockey), 52\% in Summer Olympic sports (e.g., athletics, football, swimming), and 28\% in non-Olympic sports (e.g., orienteering, floorball, Finnish baseball). There were a total of 55 different sports represented among the athletes. When the study started, a total of $44 \%$ of athletes had already competed in their sport at a national level (Finnish championship series), $38 \%$ at a European level, and $9 \%$ at an international level. To the end of the present study (at the end of the second school year), the percent of athletes competing at an international level was increased to $18.6 \%$.

\section{Procedure}

Before participant recruitment ethical approval for the data collection was obtained from the ethics committee of the University of Jyväskylä, Finland. Prior to participating to the study, all participants gave written informed consent. In Finland, informed consent from the parents/guardians of young people over 15 is not required. The data for the present study were collected during the first two years of upper secondary school: at the beginning of Grade 1 (September, Time 1; $n=391$ ), at the end of Grade 1 (March, Time 2; $n=370$ ), and at the end of Grade 2 (March, Time 3; $n=340$ ). At each of these measurement points, adolescents filled out a self-report questionnaire. The questionnaires were filled in during school hours, on the school premises. Guidelines for human subjects were followed during all stages of data collection.

A missing data analysis showed that a total of 340 athletes participated in all of the three measurement points, whereas four athletes participated only at Time 1 . A total of 47 athletes participated either at both Time 1 and Time $2(n=31)$ or, alternatively, at Time 1 and Time $3(n=$ 16). Athletes who participated at all measurement points had a higher grade point average at Time 1 $(M=8.90, S D=0.61)$ than those who did not participate at all measurement points $(M=8.51, S D=$ $0.61 ; t(386)=4.26, p<.001)$. They also placed higher utility $(\mathrm{M}=3.95, \mathrm{SD}=0.51)$ and importance $(4.07, \mathrm{SD}=0.53)$ values on school at Time 1 than those who did not participate in all measurement points $(M=3.78, S D=0.60, t(389)=2.08, p<.05 ; M=3.84, S D=0.67, t(389)=2.32, p<.05$, respectively). Boys were over-represented (adj. res $=2.1$ ) among those who did not participate in all 
measurement points $\left(\chi^{2}(1)=4.37, p<.05\right)$. Moreover, those who did not participate at all measurement points were over-represented among those who, at Time 1, planned to be professional athletes in future (adj. res $=2.8 ; \chi^{2}(1)=7.58, p<.01$ ). Missing data were not related to type of sport, sport related task values, or educational aspirations.

\section{Measures}

Task values for school work. Participants' task values in school were examined with a scale developed on the basis of work by Eccles et al. (1983) and Niemivirta (2002). The scale included 18 questions assessing interest (6 items: e.g., How much do you like math?), utility (6 items: e.g., How useful or necessary is learning math for your future plans?), and attainment (6 items: e.g., How important is it for you to get good grades in math?). Answers were given according to a 5-point Likert-scale $(1=$ not at all; $5=$ extremely much). The questions concerned math, foreign languages, and theoretical subjects. The Cronbach alpha reliabilities for the three task value sub-scales were .72, .72 , and .85 at Time 1 , respectively; $.73, .69$, and .84 at Time 2 ; and $.74, .72$, and .86 at Time 3 .

Task values for sport. Participants' task values for sport were examined by using a scale developed with reference to the scale for school values (XX et al., 2016; Authors removed for review purposes). The scale consisted of 13 questions assessing task values in the athletic context. The items concerned interest (5 items: e.g., How much do you like doing your sport?), utility (4 items: e.g., How useful or necessary is doing your sport for your future plans?), and attainment (4 items: e.g., How important is it for you to do well in sport competitions?). The values were collected for different sport-related domains, such as sport in general, sport practices, and sport competitions/games, and they were rated on a 5 -point Likert-scale $(1=$ not at all; $5=$ extremely much). The Cronbach alpha reliabilities for the three task value sub-scales were $.77, .81$, and .80 at Time 1, respectively; $.86, .78$, and .85 at Time 2 ; and $.88, .83$, and .80 at Time 3 .

Educational aspirations. Educational aspirations were examined by asking students to state the highest educational level that they planned to complete by choosing one option from the 
following possibilities: " 1 = Certificate from an upper secondary school”, " 2 = Polytechnic degree, “3 = University, master degree”, “4 = University, doctorate degree”, and "5 = I don’t have any expectations" (Lazarides et al., 2016; Rimkute et al., 2012). In the present study, the answers were recoded for statistical analyses as follows: $1=$ University degree (doctorate or master), 2 = Lower than university degree ("Polytechnic degree" or "Certificate from an upper secondary school"), and 3 $=$ No expectations ("I don't have any expectations"). Cross tabulation of the answers between T1 and $\mathrm{T} 2$, between $\mathrm{T} 2$ and $\mathrm{T} 3$, and between $\mathrm{T} 1$ and $\mathrm{T} 3$ revealed statistically significant stability in educational aspirations across time $(p<.001)$. The frequency distributions of educational aspirations at different time points are shown in Figure 1.

Athletic career aspirations. Adolescents' athletic career aspirations were examined by asking them to answer the question "Are you planning to become a professional athlete?" by selecting either "1 = yes" or " $2=$ no". Cross tabulation of the answers between T1 and T2, between T2 and T3, and between $\mathrm{T} 1$ and $\mathrm{T} 3$ revealed statistically significant stability in athletic career aspirations across time $(p<.001)$. The frequency distributions of athletic career aspirations at different time points are shown in Figure 1.

Type of sport. Adolescents were asked to report their type of sport in the questionnaire. In the analyses, the types of sports were divided into team sports (50\%) and individual sports (50\%).

Level of sport competition. The level of sport competition was assessed by asking participants to mark on questionnaire whether or not they had participated on different kind of competitions (ranging from regional to international level competitions). Based on the answers, a new variable consisting of five categories was created: $0=$ no competition experience, $1=$ competing on regional level, 2 = competing on national level (Finnish national championships), 3 = competing on European level, and $4=$ competing on international level.

Grade Point Average. Participants' grade point average (GPA) was measured by asking them to report their latest GPA. In Finnish studies, self-reported GPA has been shown to correlate 0.96 
with actual grade point average (Holopainen \& Savolainen, 2005) and, thus, to be reliable measure of GPA. From a possible range of 4 (insufficient) to 10 (excellent), the participants' GPA was, on average, $8.85(S D=0.62 ;$ Range $=7.25-10)$ at Time $1 ; 8.24(S D=0.88 ;$ Range $=5.90-10)$ at Time 2 ; and $8.05(S D=0.92 ;$ Range $=4-10)$ at Time 3 .

At Time 1, the participants' GPA in previous report card (in comprehensive school) was somewhat higher than in normative sample on average. For example, in the study by Viljaranta et al. (2009) the mean of the GPA among Finnish adolescents who were in upper secondary education was $8.53(\mathrm{SD}=0.52)$ in comprehensive school and among those in vocational school $7.30(\mathrm{SD}=0.60)$.

\section{Data Analysis}

The analyses were carried out with the following steps: First the patterns of task values involving sport and school domains that the student-athletes showed were examined (research question 1). A latent profile analysis (LPA) was conducted using interest, utility, and attainment values for both sport and school as the criteria variables. Because the data on task values were gathered at three different measurement points, the I-States as Objects (ISOA) procedure, as proposed by Bergman and El-Khouri (1999) was applied when conducting the LPA (Nurmi \& Aunola, 2005; Lazarides et al., 2016). In this procedure, the latent profiles are created independently of the time of the measurement by reorganizing the data so that each student is coded at each measurement point as a separate case (I-states). The reorganized data were then used in the LPA. The criterion variables for the recoded data were standardized and outliers $(n=4)$ that exceeded the standardized scores -3 or 3 were identified and handled by forcing them within the range -3 to 3 . The number of latent profiles was selected according to the following four criteria: (1) model fit, (2) distinguishability of the latent groups, (3) latent class sizes, and (4) theoretical justification. The fit of the model was evaluated according to the following criteria: (a) the Bayesian Information Criterion (BIC), (b) the adjusted Bayesian Information Criterion (aBIC), (c) the Akaike's Information Criterion (AIC), (d) a Vuong-Lo-Mendell-Rubin Likelihood Ratio Test (VLMR), and (e) a 
Bootstrapped Likelihood Ratio Test (BLRT). Lower information criterion values (BIC, aBIC, and AIC) indicate a better model of fit. The likelihood ratio tests (VLMR and BLRT), in turn, compare solutions with different numbers of latent classes. In these tests, a low $p$ value $(p<0.05)$ indicates that the k-1 class model has to be rejected in favor of a model with at least k classes. The distinguishability of the latent classes was evaluated with Entropy, where values closer to 1 indicate higher precision in the class solution.

Second, log linear models were used to examine the stabilities of, and changes in, latent task value patterns across time. At this stage of data analyses, the data were reorganized again into a consecutive order (at the first, second and third measurement points, each student was once again handled as three successive measurements of the same individual). Pearson's chi-square test was used as an indicator of significant associations between categorical variables across measurement points, and adjusted standardized residuals as indicators of significant differences between the observed and expected counts. Third, to examine how the identified task-value patterns were associated with athletes' educational and athletic aspirations (research question 2), multinomial and logistic regression analyses, respectively, for these aspirations at Time 1 and Time 3 were carried out, after controlling for the impacts of GPA, gender, type of sport, and level of sport competition.

The LPA was carried out by using the Mplus program (version 7.00; Muthén \& Muthén, 19982015). Assuming missingness at random (MAR), the parameters of the models were estimated using the full-information maximum likelihood estimation with standard errors that are robust against nonnormal distributions (MLR estimator; Muthén \& Muthén, 1998-2015). Log linear models and and logistic and multinomial regressions were performed with IBM SPSS Statistics 20.

\section{Results}

\section{Task-Value Patterns}

The goodness-of-fit indices for the LPAs of student-athletes' values for sport and school across three measurement points suggested that a three- or four-class solution was the best (see Table 1). 
The four-class solution had smaller BIC, aBIC, and AIC than the three-class solution, but the differences were small. The entropy value was good in both solutions, but class sizes were more reasonable in the three-class solution than in the four-class solution. Also, the VLMR test suggested that a four-class solution was no better than the three-class solution. Consequently, the three-class solution was selected as the final solution.

The first and the biggest (54\% of I-states) pattern of task values (see Table 2 for raw scores and Figure 1 for standardized scores) was characterized by high values for both sport and school. The pattern was labelled "Dual motivated". The second pattern (28\% of I-states) was characterized by placing high value on sport but low value on school, and was labelled "Low academically motivated". The third pattern ( $18 \%$ of I-states) was characterized by lower values for sport compared to the other patterns, and was thus labeled "Relatively low sport motivated".

\section{Stabilities and Changes in Motivational Patterns across Time}

The statistically significant stabilities of, and changes in, the motivational patterns from Time 1 to Time 3, analyzed by means of log linear models, are shown in Figure 2 (straight lines show changes that are more likely than expected by chance; dotted lines show changes that are less likely than expected by chance, $p<.05$ ). The results showed statistically significant associations between group membership at Time 1 and Time $2\left(\chi^{2}(4)=137.93, p<.001\right)$ and at Time 2 and Time $3\left(\chi^{2}(4)\right.$

$=112.81, p<.001)$. As shown in Figure 2, all three motivational patterns showed considerable stability across all three measurement points, that is, athletes showing a particular kind of motivational pattern at Time 1, typically showed this kind of pattern also at Time 2 and Time 3 . The results showed further that it was atypical for athletes in the dual motivated group to move either to the "Low academically motivated" group or to the "Relatively low sport motivated" group from Time 1 to Time 2 or from Time 2 to Time 3. In addition, it was atypical for athletes in the "Low academically motivated" and "Relatively low sport motivated" groups to move to the "Dual motivated" group either from Time 1 to Time 2 or from Time 2 to Time 3 . The percentage of athletes 
in the "Dual motivated" group decreased across the three measurement points, whereas the percentage of athletes in the "Relatively low sport motivated" group increased across time.

Examination of the gender distribution in the three groups showed gender differences at Time $2\left(\chi^{2}(2)=6.76, p<.05\right)$ and Time $3\left(\chi^{2}(2)=7.86, p<.05\right)$ but not at Time $1\left(\chi^{2}(2)=4.02, p\right.$ ns $)$. At Time 2 (adj. res $=2.60, p<01)$ and Time 3 (adj. res $=2.80, p<01)$ boys were statistically significantly over-represented in the "Low academically motivated" group, whereas girls were under-represented (adj. residuals $=-2.60, p<.01$ and $-2.80, p<.01$, respectively) in this group. However, after controlling for the impact of GPA, no gender differences were evident in group memberships at any of the measurement points.

Examination of the association of the type of sport with group membership showed significant associations at Time $1\left(\chi^{2}(2)=8.20, p<.05\right)$ and Time $2\left(\chi^{2}(2)=8.10, p<.05\right)$ but not at Time $3\left(\chi^{2}\right.$ $(2)=0.70, p$ ns). At Time 1 (adj. res $=2.50, p<.05)$ and Time $2(\operatorname{adj}$. res $=2.70, p<.01)$ individual sport athletes were statistically significantly over-represented in the "Relatively low sport motivated" group, whereas team sport athletes were under-represented (adj. residuals $=-2.70, p<.01)$ in this group. The differences found remained statistically significant after controlling for GPA and gender.

The level of sport competition was not associated with group membership at Time $1\left(\chi^{2}(8)=\right.$ $3.48, p=.90)$, Time $2\left(\chi^{2}(8)=2.51, p=.96\right)$ or Time $3\left(\chi^{2}(6)=1.68, p=.95\right)$.

\section{Task-Value Patterns as Predictors of Future Educational Aspirations}

Next, to examine how the task-value patterns found were associated with athletes' educational aspirations, multinomial regression analyses for educational aspirations at Time 1 and Time 3 were carried out. The results are shown in Table 3. The results for educational aspirations at the baseline (Time 1) showed that, after controlling for the GPA, gender, type of sport, and level of sport competition, compared to students in the dual motivated group, students in the low academically motivated group showed a statistically significantly higher likelihood of either having no educational 
expectations, or of planning to have less than a university degree in their future, relative to having a university degree.

The results for educational aspirations at Time 3 showed similar results: after controlling for the GPA (at Time 3), gender, type of sport, and level of sport competition, as compared to students in the dual motivated group, students who were in the low academically motivated group, either at Time 1 or at Time 3, showed a statistically significantly greater likelihood of having no educational expectations at Time 3 rather than aiming to go to university. Moreover, students in the low academically motivated group at Time 3 showed a statistically significantly greater likelihood of reporting less than a university degree as their plan rather than aiming to go to university.

\section{Task-Value Patterns as Predictors of Future Athletic Career Aspirations}

Next, to examine how the task-value patterns were associated with athletes' athletic career aspirations, logistic regression analyses for these aspirations at Time 1 and Time 3 were carried out. The results are shown in Table 4. At the baseline (Time 1), the results for athletic career aspirations showed that, after controlling for the GPA, gender, and type and competitive level of sport, as compared to the students in the Dual motivated group, the students in the Relatively low sport motivated group showed a statistically significantly greater likelihood of having no professional athletic career aspirations. The same pattern of results was found when reporting athletic career aspirations at Time 3: Compared to students in the Dual motivated group, students in the Relatively low sport motivated group showed a statistically significantly greater likelihood of having no professional athletic career aspirations at Time 3.

When using the Relatively low academically motivated pattern as the reference group instead of the Dual motivated pattern, the results showed that athletes in the Relatively low sport motivated group, either at Time 1 or at Time 3, were less likely to have professional career aspirations than those typified by a Relatively low academically motivated pattern.

\section{Discussion}


The present study simultaneously examined adolescent athletes' task values and future career aspirations during upper secondary school in two domains, sport and education. The latent profile analysis identified three different and highly stable task-value patterns among the sample: "Dual Motivated", "Low academically motivated", and "Relatively low sport motivated" patterns. The percentage of athletes demonstrating the Dual motivated pattern decreased across the first two years of upper secondary school from $63 \%$ to $47 \%$, whereas the percentage of athletes showing either the Low academically motivated pattern or the Relatively low sport motivated pattern increased from $25 \%$ to $30 \%$ and from $13 \%$ to $23 \%$, respectively. The results showed further that, compared to others, student-athletes with a "Low academically motivated" pattern were more likely to either have no educational expectations at all, or to plan to have less than a university degree in the future, rather than aim for a university degree. Athletes with a Relatively low sport motivated pattern, in turn, were less likely to have professional athletic career aspirations than those with the other types of profile.

In the present study, three different task-value patterns were identified. The most common was the "Dual motivated" pattern characterized by a high value placed on both sport and school work. At the beginning of upper secondary school, this pattern was typical for over $60 \%$ of the youth athletes. This result aligns well with those of Lupo et al. (2015) who, using a variable-oriented focus and a sample of tertiary-level European student-athletes, found that, on average, student-athletes show high motivation for both sport and education. Taken account the fact that the admission process of upper secondary sport schools in Finland is highly competitive, the result is not surprising: in order to be accepted to these schools, students have to show high level of performance not only in sports but also in their prior studies in comprehensive school and, thus, be motivated to do well in both school and sport. The results of the present study showed, however, that although the dual motivated pattern was most typical for adolescent athletes, both in the first and second grade of upper secondary sport school, the percentage of athletes demonstrating this pattern decreased over their first two years at 
school. One explanation for this result might be that, when the demands of both sport and school increase in the course of the school years, athletes either consciously or unconsciously protect themselves from overload by refocusing their values on one domain only. Stambulova and colleagues (2015) recently found that young athletes find it impossible to constantly focus equally on both sport and studies without compromising their private life and well-being. Based on these findings, Stambulova et al. (2015, p. 12) suggested that "obtaining the optimal balance should imply shifts in prioritizing sport or studies, in which the prioritized role and relevant tasks are given more time and efforts whereas the other role and relevant tasks are maintained to the degree of allowing a quick comeback when necessary." Another explanation is, however, that athletes in the present study were from the very beginning planning to study at the university_-being evident also in their high level of GPA at the beginning of the study — and, due to this, part of them have started focusing more on school as their studies progressed.

The result showing that almost a third of the student-athletes reported a relatively low value on school already at the beginning of the first grade was unexpected, particularly given that the studentathletes in the present study had all chosen to pursue the academic track in school. One explanation might be that many upper secondary sport schools in Finland have good training facilities and skilled coaches, making it easy to train at a high level, therefore athletes select the academic track even if they are not really motivated toward school and education. It is also possible that because secondary level education is common in Finland and because higher education is appreciated in the job market, adolescent athletes select this option even though they are not highly motivated in relation to academics. Overall, this pattern of motivation fits well with previous findings suggesting that student-athletes often prioritize sport over school (Adler \& Adler, 1985; Cosh \& Tully, 2014; Simons et al., 1999), which prioritization may diminish their possibility of succeeding in academics. From practical point of view, the result that about one third of the student athletes do not report high value on school suggest that other schooling possibilities to combine sport career and education than upper 
secondary school could be provided and developed for these athletes to support their subsequent employment and future prospects.

On the other hand, the fact that about 10 to $20 \%$ of student-athletes showed relatively low values for sport raises the question why those who are not highly motivated in relation to sport even apply to a sport high school. One possible explanation for this pattern is that, for some students, sport is only a hobby or a leisure activity with friends, and thus there is no genuine desire to become a high-performance athlete. This pattern typically increased during the first grade, and this may reflect the fact that upper secondary education is a transition point where standards increase both in sport and in school, and adolescents experience difficulties in adjusting to their dual career programs (Stambulova et al., 2015). Overall, this result is somewhat concerning taking into account the fact that state resources have allocated for sport high schools to support athletes' athletic careers. .

The results showed further that student-athletes' motivational patterns were very stable: the pattern typical for an athlete at the beginning of upper secondary school was very likely to remain the same until the end of grade 2. This result suggests that the motivational patterns are formed already before the first grade of upper secondary school, that is, in comprehensive school or in earlier interactions with parents, coaches, friends, and teachers. Since values and interests are socially constructed (Savickas, 2005), further studies are needed to clarify the role of different social partners, such as parents and coaches, in athletes' value development and how these shape their motivational patterns.

The second research question of the present study focused on how the patterns of task values, and the changes in them, relate to athletes' future educational and athletic career aspirations. First, in line with our hypothesis, the results showed that the task value patterns of student-athletes were associated with their future aspirations concerning education: compared to the others, studentathletes typified by a "Low academically motivated" pattern were more likely either to have no educational expectations at all, or to plan to have less than a university degree in the future, rather 
than aiming for a university degree. The fact that this result was true even after controlling for school achievement suggests that educational aspirations are not purely the consequence of achievement as reflected by grades, but that task values play an important, unique role in educational aspirations despite the level of achievement. Overall, this result is in line with the previous literature on population-based samples, according to which high academic values are positively related to academic plans and aspirations (Eccles, 2005; Lazarides et al., 2016; Viljaranta et. al, 2009; Watt, 2012).

Second, in line with our hypotheses, student-athletes' task value patterns were also associated with their athletic career aspirations. More specifically, athletes with a "Relatively low sport motivated" profile were found to be less likely to have professional athletic career aspirations than those with other kinds of motivational profiles. Overall, the results of the present study suggest that, independently of the level of achievement, a high value placed on one domain is associated with higher future aspirations in that same domain. This conclusion is in line with previous studies where, for example, girls who valued math highly were more likely to pursue science and math careers than girls who did not place a high value on those subjects (Eccles, Barber, \& Jazefowicz, 1998). The fact that already at the beginning of upper secondary school student-athletes' values are associated with their subsequent plans and aspirations concerning their future suggests that task value patterns already formed before upper secondary school might have consequences for student-athletes' later decisions in life (e.g., course enrolments, persistence in sport/school).

The novel findings of the present study should be interpreted within an understanding of its limitations. The first limitation is that the study covered only the first two years of upper secondary school. Further studies are needed to examine the stability and change, as well as the role of task value patterns in educational and athletic aspirations and concrete choices over a longer time period, for example, across all of upper secondary school and through the transition to tertiary education and/or working life. In future studies, it would be interesting to know the percentages of student 
athletes in sport upper-secondary schools who continue to university and those who become professional athletes. The second limitation is that educational and athletic aspirations were assessed using one question only. Although the answers to these questions were highly stable across the three measurement points, broader questionnaires on educational and career aspirations are recommended to get a wider and more reliable picture of the phenomena. The third limitation is that due to small sample size it was not possible to examine whether the pattern of results would be different depending on a particular sport. Because some sports, for example ice hockey, are financially more rewarded than others, it is well possible that the pattern of results is different for different sports. For example, Gonçalves, Diogo and Carvalho (JSSM, 2014), in a study with adolescent athletes in elite centers, found that motivation to compete decreased at the end of the season only in sports where the expectations of a rewarding professional sport career were low. Fourth, the sample composed only of student athletes of sport upper-secondary schools and, thus, included only academically relatively well performing students. In future studies the results reported in the present study should be compared with results found in other kind of dual-career environments and types of schools (e.g., vocational track) in order to get more insight on the phenomena under interest. Fifth, the present study focused on student athletes' task-value patterns. According to Expectancy-Value theory, however, expectations also play a role in students' career choices and commitments (Eccles et al., 1983). Consequently, future studies should be carried out to investigate the developmental processes between student athletes' task values and expectations, and the relative role of task values and expectations in adolescent' further aspirations. Finally, the study was conducted in a particular sociocultural environment, that is, in Finland. Because the pattern of results may vary in different cultural and educational settings, future cross-cultural studies are needed to discover the similarities and differences in task value patterns and educational and career aspirations of dual career athletes between countries.

\section{Conclusions}


The results of the present study increase our knowledge and understanding of student-athletes' task values and future aspirations in two different domains, sport and education. About half of the adolescent athletes were motivated in terms of task-values in both domains from the very beginning of upper secondary school, while one-third of them were motivated mainly in sports. One-fifth of the student-athletes were relatively less motivated toward sport than the others. The task value patterns were highly stable across the two year period and predicted the students' future educational and athletic aspirations. In order to support talented and/or elite athletes' construction of successful dual career pathways and prevent dropout from further education, sport, or both, an important question is how optimally to support athletes' motivation simultaneously in both sport and school during the adolescent years. Because task-value patterns seem to be formed already before upper secondary school, future research is needed to discover the role of different social agents, such as parents, coaches, and friends, in the formation of athletes' motivational patterns. 


\section{References}

Adler, P., \& Adler, P. A. (1985). From idealism to pragmatic detachment: The academic performance of college athletes. Sociology of Education, 241-250.

Bergman, L. R., \& El-Khouri, B. M. (1999). Studying individual patterns of development using IStates as Objects Analysis (ISOA). Biometrical Journal, 41, 753-770.

Bergman, L. R., \& Magnusson, D. (1991). Stability and change Berndt, T. J., \& Miller, K. E. (1990). Expectancies, values, and achievement in junior high school. Journal of Educational Psychology, 82(2), 319.

Bong, M. (2001). Role of self-efficacy and task-value in predicting college students' course performance and future enrollment intentions. Contemporary Educational Psychology, 26(4), 553-570. doi:http://dx.doi.org/10.1006/ceps.2000.1048

Bussmann, G., \& Alfermann, D. (1994). Drop-out and female athlete: A study with track-and-field athletes. In D. Hackford (Ed.), Psycho-social issues and interventions in elite sport. (pp. 89128). Frankfurt: Lang.

Christensen, M. K., \& Sørensen, J. K. (2009). Sport or school? Dreams and dilemmas for talented young Danish football players. European Physical Education Review, 26(1), 115-133. doi:10.1177/1356336X09105214

Cosh, S., \& Tully, P. J. (2014). “All I have to do is pass”: A discursive analysis of student athletes' talk about prioritising sport to the detriment of education to overcome stressors encountered in combining elite sport and tertiary education. Psychology of Sport and Exercise, 15(2), 180-189.

Durand-Bush, N., \& Salmela, J. H. (2002). The development and maintenance of expert athletic performance: Perceptions of world and Olympic champions. Journal of Applied Sport Psychology, 14(3), 154-171. 
Eccles, J. S. (2005). Subjective task value and the Eccles et al. model of achievement-related choices. In A. J. Elliot, \& C. S. Dweck (Eds.), Handbook of competence and motivation (pp. 105-121). New York: The Guilford Press.

Eccles, J. S., Adler, T. F., Futterman, R., Goff, S. B., Kaczala, C. M., Meece, J. L., \& Midgley, C. (1983). Expectancies, values, and academic behaviors. In J. T. Spence (Ed.), Advances in motivation and achievement. (pp. 75-146). San Francisco, CA: Freeman.

Eccles, J. S., Barber, B., \& Jozefowicz, D. (1998). Linking gender to educational, occupational, and recreational choices: Applying the Eccles et al. model of achievement-related choices. In W. B. Swann, J. H. Langlois \& L. A. Gilbert (Eds.), Sexism and stereotypes in modern society: The gender science of Janet Taylor Spence. (pp. 153-192). Washington, DC: APA.

Eccles, J. S., \& Harold, R. D. (1991). Gender differences in sport involvement: Applying the Eccles' expectancy-value model. Journal of Applied Sport Psychology, 3(1), 7-35. doi:10.1080/10413209108406432

Eccles, J. S., Vida, M. N., \& Barber, B. (2004). The relation of early adolescents' college plans and both academic ability and task-value beliefs to subsequent college enrollment. Journal of Adolescence, 24, 63-77.

Eccles, J., \& Wigfield, A. (2002). Motivational beliefs, values, and goals. Annual Review of Psychology, 53, 109-132. doi:10.1146/annurev.psych.53.100901.135153

EU guidelines on dual careers of athletes: Recommended policy actions in support of dual careers in high performance sport. (2012). Retrieved from http://ec.europa.eu/sport/library/documents/dual-career-guidelines-final_en.pdf

Fortes, P. C., Rodrigues, G., \& Tchantchane, A. (2010). Investigation of academic and athletic motivation on academic performance among university students. International Journal of Trade, Economics and Finance, 1(4), 367-372. 
Gaston-Gayles, J. L. (2004). Examining academic and athletic motivation among student athletes at division I university. Journal of College Student Development, 45(1), 75-83.

Gonçalves, C., E., Diogo, F. L., \& Carvalho, H. M. (2014). A multilevel approach to the path to expertise in three different competitive settings. Journal of Sports Science and Medicine, 13, 166-171.

Holopainen, L., \& Savolainen, H. (2005). The validity of self-reported grade point average. Unpublished raw data. Jyväskylä. Finland: University of Joensuu and University of Jyväskylä.

Jõesaar, H., Hein, V., \& Hagger, M. S. (2011). Peer influence on young athletes' need satisfaction, intrinsic motivation and persistence in sport: A 12-month prospective study. Psychology of Sport and Exercise, 12(5), 500-508. doi:http://dx.doi.org/10.1016/j.psychsport.2011.04.005

Kuh, G. D., Cruce, T. M., Shoup, R., Kinzie, J., \& Gonyea, R. M. (2008). Unmasking the effects of student engagement on first-year college grades and persistence. The Journal of Higher Education, 79(5), 540-563.

Lally, P. S., \& Kerr, G. A. (2005). The career planning, athletic identity, and student role identity of intercollegiate student athletes. Research Quarterly for Exercise and Sport, 76(3), 275-285.

Lazarides, R., Viljaranta, J., Aunola, K., Pesu, L., \& Nurmi, J.-E. (2016). The role of parental expectations and students' motivational profiles for educational aspirations. Learning and Individual Differences, 51, 29-36. doi:10.1016/j.lindif.2016.08.024

Lupo, C., Guidotti, F., Goncalves, C. E., Moreira, L., Doupona Topic, M., Bellardini, H., \& Capranica, L. (2015). Motivation towards dual career of European student-athletes. European Journal of Sport Science, 15(2), 151-160. doi:10.1080/17461391.2014.940557

Lupo, C., Mosso, C. O., Guidotti, F., Cugliari, G., Pizzigalli, L., \& Rainoldi A. (2017). The Adapted Italian version of the Baller Identity Measurement Scale to evaluate the student-athletes' identity in relation to gender, age, type of sport, and competition level. Plos One, 12(1), Article number 0169278. 
Lupo, C., Mosso, C. O., Guidotti, F., Cugliari, G., Pizzigalli, L., \& Rainoldi, A. (in press a).

Motivation toward dual-career of Italian student-athletes enrolled in different university paths. Sport Sciences for Health.

Lupo, C., Brustio, P. R., Valentic, E., Kiendl, D., Wenzel, R., ..., Guidotti, F. (in press b). The use of Focus Group Interviews to define the perceived importance of competencies related to the entrepreneurship as starting point for a new career in European athletes: an AtLETyC study. Sport Sciences for Health.

McCarthy, P. J., Jones, M. V., \& Clark-Carter, D. (2008). Understanding enjoyment in youth sport: A developmental perspective. Psychology of Sport and Exercise, 9(2), 142-156. doi: http://dx.doi.org/10.1016/j.psychsport.2007.01.005

Meece, J. L., Glienke, B. B., \& Burg, S. (2006). Gender and motivation. Journal of School Psychology, 44(5), 351-373.

Muthén, L. K., \& Muthén, B. O. (1998-2015). Mplus user's guide. Los Angeles, CA: Muthén \& Muthén.

Mäkikangas, A., Tolvanen, A., Aunola, K., Feldt, T., Mauno, S., \& Kinnunen, U. (in press). Multilevel Latent Profile Analysis with covariates: Identifying job characteristics profiles in hierarchical data as an example. Organizational Research Methods.

Nurmi, J-E. (1989). Development of orientation to the future during early adolescence: a four-year longitudinal study and two cross-sectional comparisons. International Journal of Psychology, 24, 195-214. DOI: 10.1080/00207594.1989.10600042

Nurmi, J-E., Seginer, R., \& Poole, M. E. (1995). Searching for the future in different environments. A comparison of Australian, Finnish and Israeli adolescents' future orientation, explorations and commitments. In P. Noack, Hofer, M., \& Youniss, J. (Eds.), Psychological responses to social change: Human development in changing environments (pp. 219-238). Berlin: de Gruyter. 
Nurmi, J., \& Aunola, K. (2005). Task-motivation during the first school years: A person-oriented approach to longitudinal data. Learning and Instruction, 15(2), 103-122. doi:http://dx.doi.org/10.1016/j.learninstruc.2005.04.009

Pelletier, L. G., Fortier, M. S., Vallerand, R. J., \& Brière, N. M. (2001). Associations among perceived autonomy support, forms of self-regulation, and persistence: A prospective study. Motivation \& Emotion, 25(4), 279-306.

Pintrich, P. R. (2003). A motivational science perspective on the role of student motivation in learning and teaching contexts. Journal of Educational Psychology, 95(4), 667.

Pless, M. (2014). Stories from the margins of the educational system. Journal of Youth Studies, 17(2), 236-251. doi:10.1080/13676261.2013.815700

Purdy, D. A., Eitzen, D. S., \& Hufnagel, R. (1982). Are athletes also students? The educational attainment of college athletes. Social Problems, 29(4), 439-448.

Rimkute, L., Hirvonen, R., Tolvanen, A., Aunola, K., \& Nurmi, J.-E. (2012). Parents' role in adolescents' educational expectations. Scandinavian Journal of Educational Research, 56 (6), 571-590. doi:10.1080/00313831.2011.621133

Sarrazin, P., Vallerand, R., Guillet, E., Pelletier, L., \& Cury, F. (2002). Motivation and dropout in female handballers: A 21-month prospective study. European Journal of Social Psychology, 32(3), 395-418. doi:10.1002/ejsp.98

Savickas, M. L. (2005). The theory and practice of career construction. In S. D. Brown \& R. W. Lent (Eds.), Career development and counseling: Putting theory and research to work (pp. 42-70). Hoboken, NJ: Wiley.

Simons, H. D., Van Rheenen, D., \& Covington, M. V. (1999). Academic motivation and the student athlete. Journal of College Student Development, 40(2), 151-162. 
Stambulova, N. B., Engström, C., Franck, A., Linnér, L., \& Lindahl, K. (2015). Searching for an optimal balance: Dual career experiences of Swedish adolescent athletes. Psychology of Sport and Exercise, 21, 4-14.

Stambulova, N. B., \& Wylleman, P. (2015). Dual career development and transitions. In N. Stambulova \& P. Wylleman (Eds.), Psychology of Sport and Exercise, 21. Special issue. doi:http://dx.doi.org/10.1016/j.psychsport.2015.05.003

Stambulova, N. B., Engström, C., Franck, A., Linnér, L., \& Lindahl, K. (2015). Searching for an optimal balance: Dual career experiences of Swedish adolescent athletes. Psychology of Sport and Exercise, 21, 4-14. http://dx.doi.org/10.1016/j.psychsport.2014.08.009

Umbach, P. D., Palmer, M. M., Kuh, G. D., \& Hannah, S. J. (2006). Intercollegiate athletes and effective educational practices: Winning combination or losing effort? Research in Higher Education, 47(6), 709-733.

Vallerand, R. J., Fortier, M. S., \& Guay, F. (1997). Self-determination and persistence in a real-life setting: Toward a motivational model of high school dropout. Journal of Personality and Social Psychology, 72(5), 1161-1176.

Viljaranta, J., Nurmi, J., Aunola, K., \& Salmela-Aro, K. (2009). The role of task values in adolescents' educational tracks: A person-oriented approach. Journal of Research on Adolescence, 19(4), 786-798. doi:10.1111/j.1532-7795.2009.00619.x

Watt, H.M. G., Shapka, J. D., Morris, Z., A. et al. (2012). Gendered motivational processes affecting High School mathematics participation, educational aspirations, and career plans: A comparison of samples from Australia, Canada, and the United States. Developmental Psychology, 48(6), 1594-1611.

Wigfield, A., \& Eccles, J. S. (2000). Expectancy-value theory of achievement motivation. Contemporary Educational Psychology, 25(1), 68-81. 
Wylleman, P., \& Lavallee, D. (2004). A developmental perspective on transitions faced by athletes. In M. Weiss (Ed.), Developmental sport and exercise psychology: A lifespan perspective (pp. 507-527). Morgantown, WV: FIT.

Wylleman, P., Reints, A., \& De Knop, P. (2013). A developmental and holistic perspective on athletic career development. In P. Sotiaradou, \& V. De Bosscher (Eds.), Managing high performance sport (pp. 159-182). New York, NY: Routledge. 


\section{Table 1}

Model Fit Indices and Class Frequencies for Latent Profile Analyses with Different Numbers of Latent Profiles of Student-Athletes' Task Values in Sport and School (N of I-states $=1118)$

\begin{tabular}{|c|c|c|c|c|c|c|c|}
\hline \multirow[t]{2}{*}{ Number of Groups } & \multirow[t]{2}{*}{$\mathrm{BIC}$} & \multirow[t]{2}{*}{$\mathrm{aBIC}$} & \multirow[t]{2}{*}{ AIC } & \multirow[t]{2}{*}{ Entropy } & \multirow{2}{*}{$\begin{array}{l}\text { p-Value } \\
\text { of } \\
\text { VLMR }\end{array}$} & \multirow{2}{*}{$\begin{array}{l}\text { p-Value } \\
\text { of } \\
\text { BLRT }\end{array}$} & \multirow{2}{*}{$\begin{array}{l}\text { Number of } \\
\text { estimated } \\
\text { para-meters }\end{array}$} \\
\hline & & & & & & & \\
\hline $1(\mathrm{~N}=1118)$ & 18366.20 & 18328.08 & 18305.97 & - & - & - & 12 \\
\hline $2\left(\mathrm{n}_{1}=216, \mathrm{n}_{2}=902\right)$ & 17466.62 & 17406.27 & 17371.25 & 0.860 & $<.0001$ & $<.0001$ & 19 \\
\hline $3\left(n_{1}=197, n_{2}=314\right.$, & 16905.59 & 16823.00 & 16775.08 & 0.782 & $<.0001$ & $<.0001$ & 26 \\
\hline \multicolumn{8}{|l|}{$\left.n_{3}=607\right)$} \\
\hline $4\left(\mathrm{n}_{1}=82, \mathrm{n}_{2}=449\right.$ & 16741.55 & 16636.73 & 16575.91 & 0.777 & 0.1782 & $<.0001$ & 33 \\
\hline $\left.\mathrm{n}_{3}=416, \mathrm{n}_{4}=171\right)$ & & & & & & & \\
\hline
\end{tabular}

Note. Selected Solution in Bold. 


\section{Table 2}

Means (M) and Standard Deviations (SD) of the Task Value Variables for the Three Identified Motivational Patterns

\begin{tabular}{|c|c|c|c|c|}
\hline & \multicolumn{3}{|c|}{ Motivational Patterns } & \multirow[b]{2}{*}{$\begin{array}{l}(n \text { of I-states }= \\
1118)\end{array}$} \\
\hline & $\begin{array}{l}\text { Low } \\
\text { academically } \\
\text { motivated } \\
\text { ( } \text { of I-states }= \\
314 \text { ) }\end{array}$ & $\begin{array}{l}(n \text { of I-states }= \\
607)\end{array}$ & $\begin{array}{l}\text { Relatively low } \\
\text { sport motivated } \\
\text { ( } \text { n of I-states }= \\
197 \text { ) }\end{array}$ & \\
\hline \multicolumn{5}{|c|}{ Interest value / sport } \\
\hline$M$ & $4.77^{\mathrm{a}}$ & $4.78^{\mathrm{a}}$ & $3.89^{\mathrm{b}}$ & 4.61 \\
\hline$S D$ & 0.28 & 0.30 & 0.52 & 0.48 \\
\hline \multicolumn{5}{|c|}{ Utility value / sport } \\
\hline$M$ & $4.74^{\mathrm{a}}$ & $4.74^{\mathrm{a}}$ & $3.89^{\mathrm{b}}$ & 4.59 \\
\hline$S D$ & 0.36 & 0.34 & 0.59 & 0.52 \\
\hline \multicolumn{5}{|c|}{$\begin{array}{l}\text { Attainment value / } \\
\text { sport }\end{array}$} \\
\hline$M$ & $4.58^{\mathrm{a}}$ & $4.61^{\mathrm{a}}$ & $3.89^{\mathrm{b}}$ & 4.47 \\
\hline$S D$ & 0.40 & 0.42 & 0.55 & 0.52 \\
\hline \multicolumn{5}{|c|}{ Interest value / school } \\
\hline$M$ & $2.75^{\mathrm{a}}$ & $3.62^{\mathrm{b}}$ & $3.12^{\mathrm{c}}$ & 3.29 \\
\hline$S D$ & 0.47 & 0.47 & 0.52 & 0.61 \\
\hline \multicolumn{5}{|c|}{ Utility value / school } \\
\hline$M$ & $3.33^{\mathrm{a}}$ & $4.20^{\mathrm{b}}$ & $3.61^{\mathrm{c}}$ & 3.85 \\
\hline$S D$ & 0.41 & 0.38 & 0.48 & 0.56 \\
\hline \multicolumn{5}{|c|}{$\begin{array}{l}\text { Attainment value / } \\
\text { school }\end{array}$} \\
\hline$M$ & $3.40^{\mathrm{a}}$ & $4.27^{\mathrm{b}}$ & $3.76^{\mathrm{c}}$ & 3.93 \\
\hline$S D$ & 0.55 & 0.44 & 0.57 & 0.63 \\
\hline
\end{tabular}

Note. Group means with different superscripts show a statistically significant difference $(p<0.05)$. 


\section{Table 3}

Motivational Patterns as Predictors of Educational Aspirations at Time 1 and Time 3 (Multinomial Regression Analyses)

Low academically motivated ${ }^{\mathrm{b}}$

Relatively low sport motivated

GPA T1

Level of sport competition T1

Gender $^{\mathrm{c}}$

Type of sport ${ }^{\mathrm{d}}$

Low academically motivated ${ }^{\mathrm{b}}$

Relatively low sport motivated ${ }^{\mathrm{b}}$

GPA T1

Level of sport competition T1

Gender $^{\mathrm{c}}$
Predictor Variable

Educational aspirations T1
$\mathrm{b}(\mathrm{SE})$

Wald $\chi^{2}(\mathrm{df}=1)$

OR

No expectations $\mathrm{s}^{\mathrm{a}}$

$\begin{array}{lcc}1.05(0.42)^{*} & 6.17 & 2.84 \\ 0.23(0.52) & 0.19 & 1.25 \\ -1.28(0.31)^{* * *} & 16.86 & 0.28 \\ 0.10(0.22) & 0.19 & 1.10 \\ -1.07(0.41)^{* *} & 6.95 & 0.34 \\ -0.00(0.37) & 0.00 & 1.00 \\ 1.20(0.30)^{* * *} & 15.76 & 3.33 \\ -0.13(0.37) & 0.13 & 0.88 \\ -0.58(0.21)^{* *} & 7.29 & 0.56 \\ 0.19(0.15) & 1.65 & 1.20 \\ 0.28(0.24) & 1.32 & 1.32\end{array}$


Educational aspirations T3

\begin{tabular}{|c|c|c|c|c|}
\hline \multirow[t]{8}{*}{ Lower than university ${ }^{\mathrm{a}}$} & Low academically motivated ${ }^{\mathrm{b}} \mathrm{T} 1$ & $0.55(0.40)$ & 1.84 & 1.73 \\
\hline & Relatively low sport motivated $^{\mathrm{b}} \mathrm{T} 1$ & $0.72(0.48)$ & 2.19 & 2.04 \\
\hline & Low academically motivated ${ }^{\mathrm{b}} \mathrm{T} 3$ & $1.58(0.42)^{* * *}$ & 14.41 & 4.83 \\
\hline & Relatively low sport motivated $^{\mathrm{b}} \mathrm{T} 3$ & $0.78(0.46)$ & 2.92 & 2.19 \\
\hline & GPA T3 & $-0.83(0.19)^{* * *}$ & 18.76 & 0.44 \\
\hline & Level of sport competition T3 & $0.21(0.21)$ & 1.00 & 1.24 \\
\hline & Gender $^{\mathrm{d}}$ & $-0.12(0.34)$ & 0.13 & 0.89 \\
\hline & Type of sport ${ }^{\mathrm{c}}$ & $-0.19(0.34)$ & 0.32 & 0.83 \\
\hline \multirow[t]{6}{*}{ No expectations ${ }^{\mathrm{a}}$} & Low academically motivated ${ }^{\mathrm{b}} \mathrm{T} 1$ & $1.36(0.43)^{* *}$ & 9.97 & 3.90 \\
\hline & Relatively low sport motivated ${ }^{\mathrm{b}} \mathrm{T} 1$ & $0.14(0.64)$ & 0.05 & 1.15 \\
\hline & Low academically motivated ${ }^{\mathrm{b}} \mathrm{T} 3$ & $2.08(0.49)^{* * *}$ & 18.25 & 8.03 \\
\hline & Relatively low sport motivated ${ }^{\mathrm{b}} \mathrm{T} 3$ & $0.87(0.53)$ & 2.68 & 2.39 \\
\hline & GPA T3 & $-0.16(0.22)$ & 0.53 & 0.85 \\
\hline & Level of sport competition T3 & $0.82(0.24)^{* *}$ & 11.28 & 2.27 \\
\hline
\end{tabular}


${ }^{\text {a }}$ Reference group University

${ }^{\mathrm{b}}$ Reference group Dual motivated

${ }^{\mathrm{c}}$ Female vs. Male

${ }^{\mathrm{d}}$ Individual vs. Team sport 


\section{Table 4}

Motivational Profiles as Predictors of Athletic Career Aspirations at Time 1 and Time 3 (Logistic Regression Analyses)

Predictor Variable

Athletic Career Aspirations T1

\begin{tabular}{|c|c|c|c|}
\hline Low academically motivated ${ }^{\mathrm{b}} \mathrm{T} 1$ & $-0.08(0.40)$ & 0.04 & 0.93 \\
\hline Relatively low sport motivated ${ }^{\mathrm{b}} \mathrm{T} 1$ & $1.48(0.38)^{* * *}$ & 15.06 & 4.40 \\
\hline GPA T1 & $1.31(0.27)^{* * *}$ & 22.97 & 3.69 \\
\hline Level of sport competition T1 & $0.17(0.17)$ & 1.00 & 1.18 \\
\hline Gender ${ }^{\mathrm{c}}$ & $0.71(0.28)^{*}$ & 6.39 & 2.04 \\
\hline Type of sport ${ }^{d}$ & $-0.28(0.28)$ & 0.95 & 0.76 \\
\hline
\end{tabular}

Athletic Career Aspirations T3

Non-professional ${ }^{\mathrm{a}}$

$\begin{array}{llcc}\text { Low academically motivated }^{\mathrm{b}} \mathrm{T} 1 & -0.64(0.35) & 3.39 & 0.53 \\ \text { Relatively low sport motivated } & \\ \text { Low } \mathrm{T} 1 & 0.60(0.44) & 1.86 & 1.82 \\ \text { Relatively low sport motivated }^{\mathrm{b}} \mathrm{T} 3 & 1.30(0.35)^{* * *} & 14.57 & 0.59\end{array}$




$\begin{array}{llcc}\text { GPA T3 } & 0.32(0.15)^{*} & 4.66 & 1.38 \\ \text { Level of sport competition T3 } & 0.18(0.16) & 1.24 & 1.19 \\ \text { Gender }^{\mathrm{c}} & 0.68(0.26)^{* *} & 6.95 & 1.98 \\ \text { Type of sport }^{\mathrm{d}} & 0.04(0.26) & 0.03 & 1.04\end{array}$

${ }^{a}$ Reference group Professional

${ }^{\mathrm{b}}$ Reference group Dual motivated

${ }^{\mathrm{c}}$ Female vs. Male

${ }^{\mathrm{d}}$ Individual vs. Team sport 


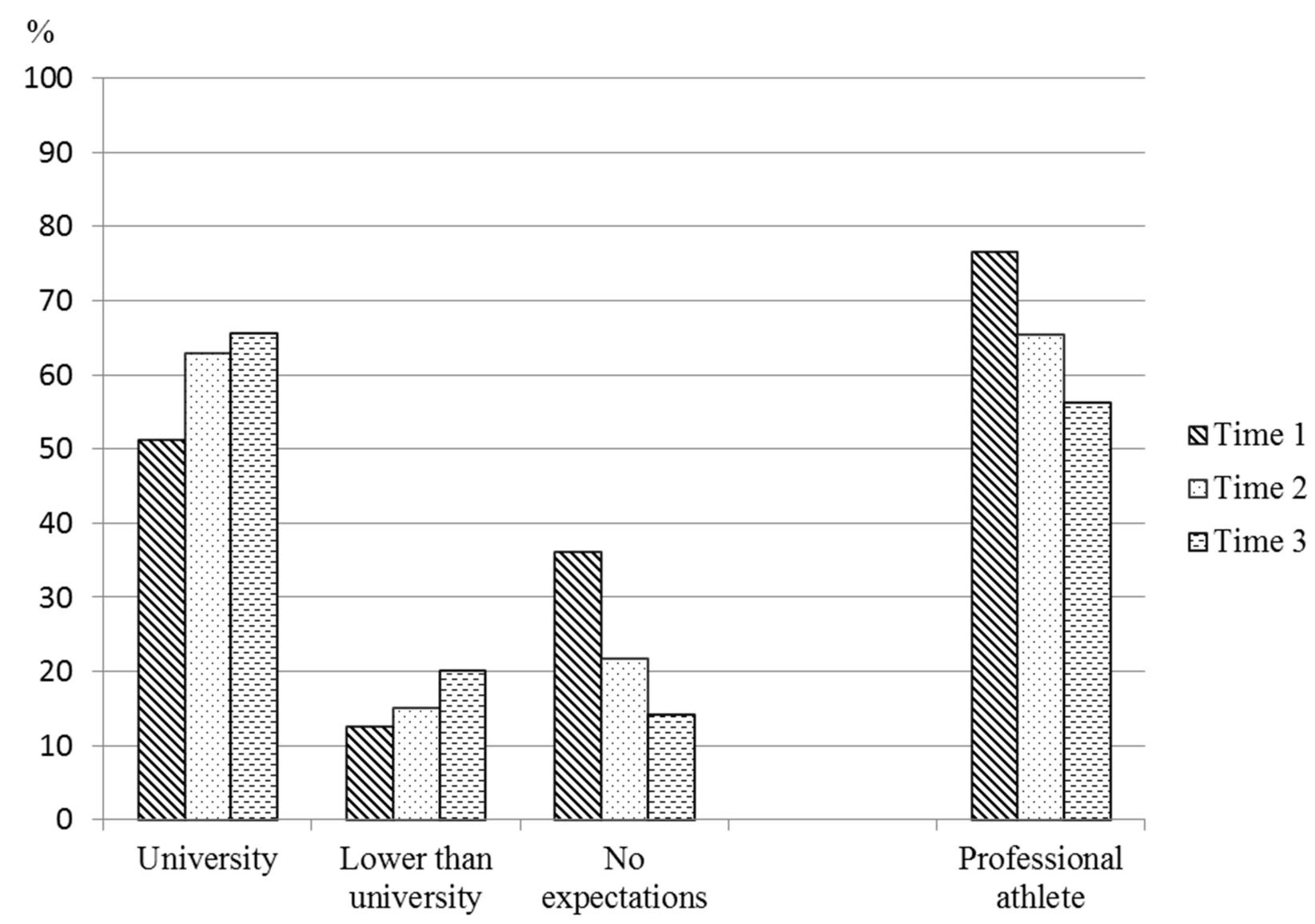

Educational aspirations

Athletic career aspirations

Figure 1. Frequency distributions (percentages) of student athletes' educational and athletic career aspirations at different time points. 


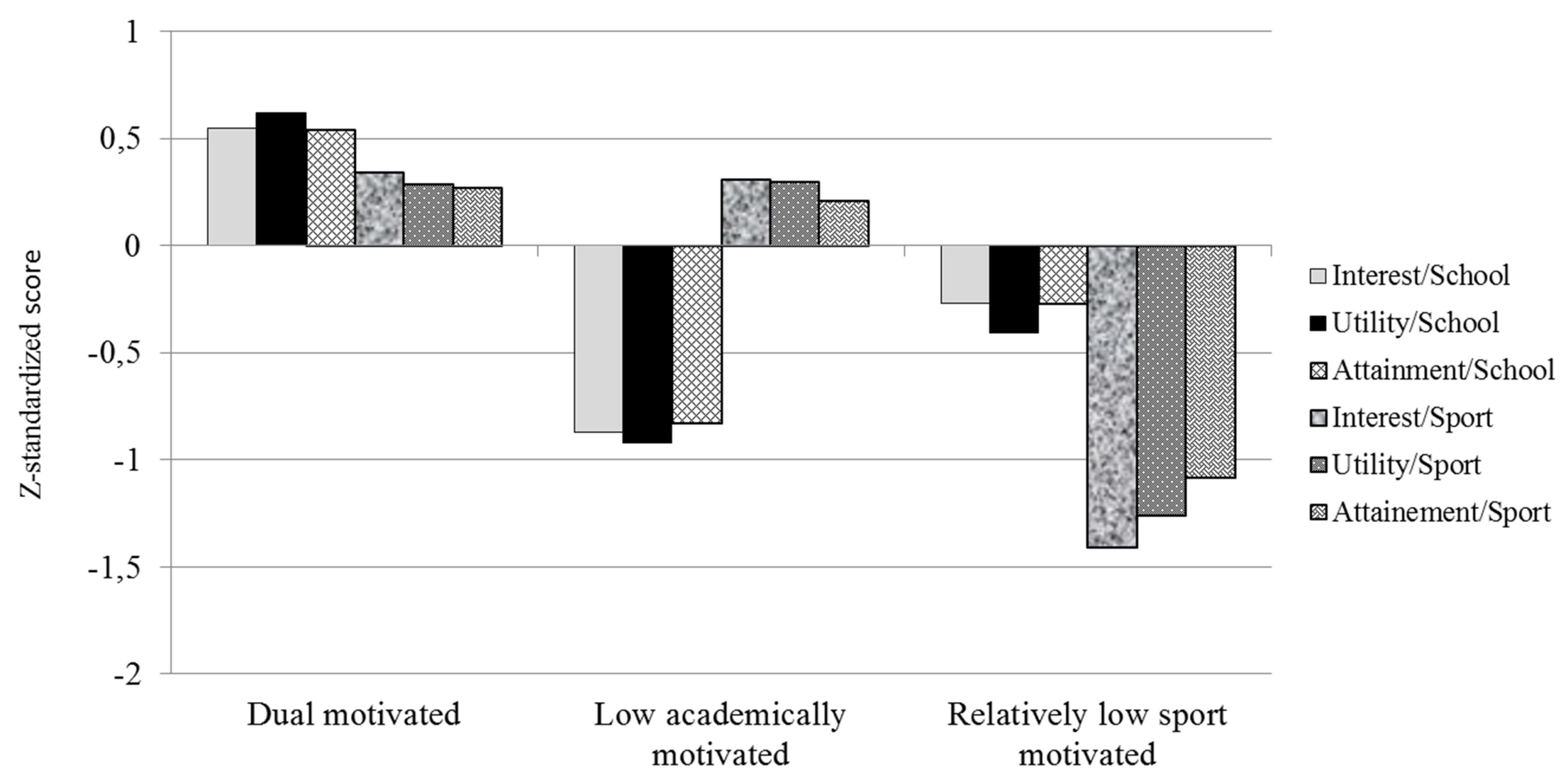

Figure 2. Standardized scores of criteria variables in different motivational profiles (N of I-states $=1118)$. 


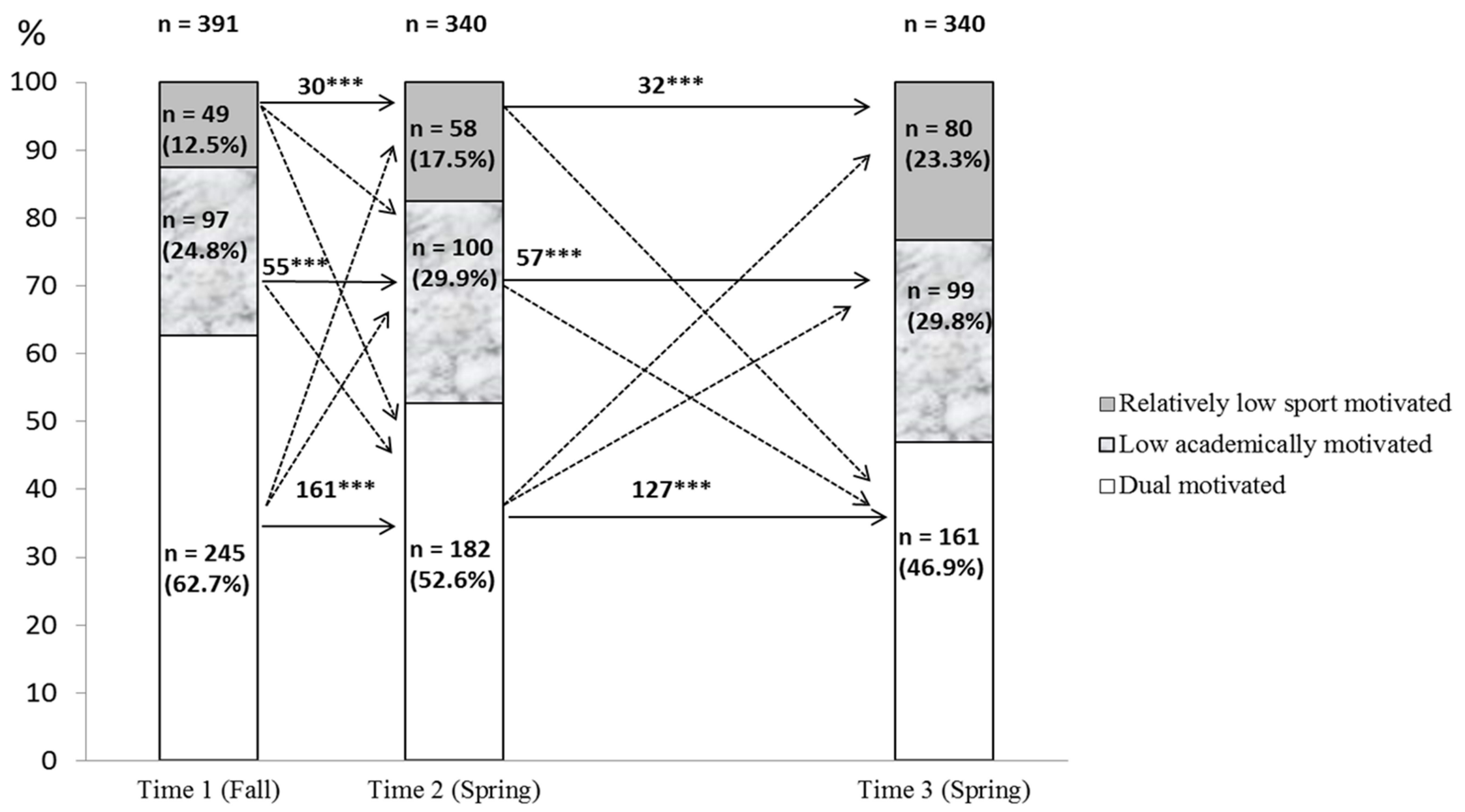

Upper secondary school / Grade 1
Upper secondary school /

Grade 2

Figure 3. Statistically significant stabilities and changes in group membership across different measurements (frequencies; straight line for changes that are more likely than expected by chance; dotted lines for changes that appear less likely than expected by chance, $\mathrm{p}<.05)$ when tested with log linear models. Note. $* * * p<0.001$. 